\title{
Cardiac manifestations of COVID-19
}

\author{
Agata Bielecka-Dabrowa ${ }^{1,2}$, Anna Cichocka-Radwan ${ }^{2, *}$, Joanna Lewek ${ }^{1,2}$, Filip Pawliczak ${ }^{1,2}$, Marek Maciejewski ${ }^{2}$, \\ Maciej Banach ${ }^{1,2}$ \\ ${ }^{1}$ Department of Preventive Cardiology and Lipidology, Chair of Nephrology and Hypertension, Medical University of Lodz, Rzgowska 281/289, 93-338 Lodz, \\ Poland \\ ${ }^{2}$ Department of Cardiology and Congenital Diseases of Adults, Heart Failure Unit, Polish Mother's Memorial Hospital Research Institute (PMMHRI), \\ Rzgowska 281/289, 93-338 Lodz, Poland \\ *Correspondence: aniacichocka3o@wp.pl (Anna Cichocka-Radwan)
}

\section{DOI:10.31083/j.rcm2202043}

This is an open access article under the CC BY 4.0 license (https://creativecommons.org/licenses/by/4.0/).

Submitted: 14 March 2021 Revised: 19 May 2021 Accepted: 20 May 2021 Published: 30 June 2021

COVID-19 is a novel viral infection caused by severe acute respiratory syndrome (SARS) beta-coronavirus. Epidemiological status changes dynamically as the pandemy is far from ending. Several complications of presented virus may be similar to those observed in other viral infections. Despite lacking data, the heart involvement may be comparable to cardiac complications observed previously in those with SARS as well as Middle East Respiratory Syndrome (MERS). In COVID-19 we observe elevated levels of cardiac biomarkers, such as natriuretic peptides, troponins, myoglobin, C-reactive protein (CRP), interleukin-2 (IL-2), interleukin-6 (IL-6) and ferritin, which is likely the result of myocardial injury. The possible mechanisms of cardiovascular injury include direct toxicity through the viral invasion of cardiac myocytes, ACE-2 receptor-mediated CV (cardiac and endothelial) injury, microvascular dysfunction and thrombosis and cytokine release syndrome (mainly IL-6 mediated). Cardiac manifestations of COVID-19 are focal or global myocardial inflammation, necrosis, ventricular dysfunction, heart failure and arrhythmia.

\section{Keywords}

COVID-19; Coronavirus; SARS-CoV-2; Heart failure; Cardiac manifestations

\section{Introduction}

Viral infection is known as one of the most common infectious causes of myocarditis, most often in influenza or parvovirus B-19 infection [1, 2]. It has been widely described that during influenza infection, elderly patients with cardiovascular diseases have higher rates of heart failure-related events, cardiac arrhythmias and acute coronary syndromes [3]. The reasons underlying this may be connected with increased viscosity during febrile illnesses, procoagulation and proinflammatory effects or endothelial cell dysfunction $[3,4]$. Previous severe acute respiratory syndrome (SARS) beta-coronavirus infections were associated with symptoms of heart failure and arrhythmias [4]. It is difficult to expect that this might differ in case of coronavirus disease 2019 (COVID-19), caused by SARS-CoV [4]. The first observations were focused on respiratory problems often with hypoxic respiratory failure and bilateral infiltrates on computed tomography [5]. Complications from different organs have also been diagnosed, including cardiovascular manifestations, as one of the most important that essentially effect the prognosis. It seems that the heart injury in patients with COVID19 may be comparable to cardiac complications observed previously in those with SARS as well as Middle East Respiratory Syndrome (MERS), but we are still lacking data. Cardiac injury may be a direct manifestation of COVID-19. On the other hand, it can be a complication of acute lung injury [6]. In addition, elevated filling pressure and exacerbation of heart failure may also play a role in lung failure caused by SARS-CoV-2 [6].

\section{Search strategy}

We searched the electronic database PUBMED (2019 to 2021). Furthermore, abstracts from national and international cardiovascular meetings, summaries of product characteristicsand selected monographs were searched. The main data search terms were: cardiac manifestations, coronavirus, COVID-19, heart failure, SARS-CoV-2, severe acute respiratory syndrome.

\subsection{Epidemiology of COVID-19}

COVID-19 is the public health challenge of the century. The pandemic is spreading dynamically across the world and any information published may soon need to be updated. In the beginning of the COVID-19 outbreak the most valuable and complete data were provided by Chinese researchers, as this country was the first one to successfully reduce both transmission and mortality [7]. The epidemiological data are still difficult to summarize as the number of patients tested positive as well as fatalities increases daily. Another issue with the data is their regional variability depending on the onset of the epidemic in each country and the healthcare efficiency as a derivative of growth in cases.

SARS-CoV-2 is highly contagious, although it is not very lethal. At the time this article was written 142,066,934 confirmed cases globally had resulted in 3,034,412 deaths and $120,633,661$ recoveries [8]. The situation is not evenly distributed across the world, as the most severely affected re- 
gions are both Americas (mostly the USA \& Brasil), Europe (France, Russia and UK leading the statistics) \& Asia (India \& Indonesia with the highest numbers of detected positive patients) [9]. The global fatality rate estimation so far is approximately $2.13 \%$, although we present also ongoing cases, so the final result may vary. It is important to acknowledge the fact the case fatality rate differ across the world and it is highly dependent on the local healthcare capacity, prevention and vaccination strategies and initial testing of any suspicious cases. It may also correlate with the number of cases as the waves of the infection are connected with higher fatality and overall mortality. The mortality rate increases among patients older than 60 years up to $8.8 \%$, while it stays low for under 60 years old patients-0.46\% [10]. The US research shows differences in prevalence and mortality among races as COVID-19 infection occurs with higher probability in Latino and African American vs "white" individuals (1000 and 925 vs 389 per 100,000 respectively) and is more fatal in the African American group vs Latino and white individuals (73 vs 36 and 22 per 100,000 respectively) [11].

\subsection{Risk factors and the course of COVID-19 with cardiac manifestation}

The mortality risk factors in patients with COVID-19 are: obesity, hypertension, diabetes, chronic lung, cardiac, hepatic and kidney diseases, cancers, immunodeficiencies and pregnancy [12]. To be precise according to cardiovascular diseases the main risk factors are coronary artery disease, heart, arrhythmias and current tobacco smoking. In fact, cardiovascular comorbidities occurring with SARS-CoV-2 can be both risk factors of poor outcome and eventually manifestations of COVID-19 itself. Furthermore, they are markers of bad prognosis as myocardial damage and heart failure are associated with $40 \%$ of deaths in Wuhan [13]. Many of patients with a severe course of the disease had increased plasma high-sensitivity troponin-I ( $>28 \mathrm{pg} / \mathrm{mL}$ : $46 \%$ among nonsurvivors vs $1 \%$ among survivors) and Ddimer $(>1 \mu \mathrm{g} / \mathrm{mL}$ : $81 \%$ among non-survivors vs $24 \%$ survivors) [14]. Further research also provides valuable data on $\mathrm{N}$-terminal proBtype natriuretic peptide (NT-proBNP) levels, which were increased in approximately $27.5 \%$ of infected patients [15]. NTproBNP can be an independent risk factor as higher values $(>88.64 \mathrm{pg} / \mathrm{mL})$ predicted higher risk of death with sensitivity of $100 \%$ and specificity of $66.67 \%$ [16].

Most common cardiac manifestations in symptomatic SARS-CoV-2 patients are arrhythmias (16.7\%) with ventricular tachycardia/fibrillation (5.9\%) [17], shock (7-8.7\%) $[18,19]$, acute myocardial injury (7.2\%), chest pain $(3.4 \%)$, and ST-depression on electrocardiogram (ECG) (0.7\%) [20]. Zhou et al. [14] found high prevalence of heart failure (23\%) as an extrapulmonary manifestation of infection and the rate was higher (52\%) in non-survivors. It is still debatable if it is caused by viral affliction of myocardium or as a result of cytokine storm and a rapid inflammatory response. There are cases of acute myocarditis developing before the pulmonary symptoms; thus ventricular tachyarrhythmias may become the first clinical manifestation of COVID-19 infection and leads to increased risk of sudden cardiac death [21, 22].

Survival of cardiac arrests of inpatients in Wuhan was poor. Restoration of spontaneous circulation (ROSC) among 136 patients was reported in 18 patients ( $13.2 \%)$, while only 4 (2.9\%) survived for at least 30 days and 1 was in a favorable neurological condition [23]. The main cause of cardiac arrest was respiratory $(87.5 \%)$ and at the onset of resuscitation the most common rhythm was asystole (89.7\%), while pulseless electrical activity (PEA-4.4\%) and shockables were the rarest (5.9\%) [23].

The early US data gathered after the outbreak in New York City provided initial information about 5700 cases hospitalized due to infection [24]. 2634 patients had reached the outcome of death (21\%) or discharge, $14.2 \%$ been treated invasively at the ICU and $12.2 \%$ required use of mechanical ventilators. Among hospitalized patients the most common comorbidities were hypertension (56.6\%), obesity (41.7\%) and diabetes (33.8\%). For comparison, American prevalence for hypertension is $33.2 \%$, obesity $39.8 \%$ and diabetes $15 \%$ [25].

Despite the early data, year after global coronavirus outbreak there was also observed strong relation between coexistence of cancers with cardiovascular diseases and high-risk of death due to COVID-19. Patients with cancers and cardiac comorbidities died more frequently in comparison with cancer ( $35 \%$ vs $17 \% ; P=0.004)$ or cardiovascular disease solely (35\% vs $21 \% ; P=0.009$ ) [26].

\subsection{Pathophysiology of cardiac involvement in COVID-19}

In patients with SARS-CoV-2 one of the observations is an elevated level of cardiac biomarkers, such as natriuretic peptides, troponins, myoglobin, C-reactive protein (CRP), interleukin-2 (IL-2), interleukin-6 (IL-6) and ferritin, which is likely the result of myocardial injury $[19,27,28]$. It was confirmed by $\mathrm{Xu} \mathrm{Z}$ et al. [27], that myocardium of patients with SARS-CoV-2 infection was infiltrated with inflammatory cells. Such viral invasion of cardiac myocytes remains one of the mechnisms of cardiac involvement, which can explain the development of myocarditis frequently observed in cardiac magnetic resonance imaging and echocardiography of COVID-19 patients. On the other hand, the most likely explanation for increased levels of these biomarkers is direct cardiac involvement leading to cardiac apoptosis. Other possible explanations include hypoxia, tachycardia, arrhythmias, myocarditis, microvascular dysfunction, thrombosis, Takotsubo cardiomyopathy and auto-immune-like mechanisms related to the release of proinflammatory cytokines $[29,30]$. There have been a few attempts described worldwide to explain cardiac toxicity mechanisms in COVID-19 patients. SARS-CoV-2 enters the cell by a host receptor angiotensin-converting enzyme 2 (ACE2) [31, 32]. ACE2 protein, which is expressed in the lungs, heart and vessels, is a convertase capable of angiotensin II to angiotensin (17) and angiotensin I to angiotensin (1-9) transformation. Those proteins have cardioprotective activity [33]. On the other hand, ACE2 binds the SARS-CoV-2 spike protein and 
transfers it into lung alveolar epithelial cells [34] by cell surface associated transmembrane protein serine 2 (TMPRSS2) [35]. The SARS-CoV-2 infection leads to dysregulation of the renin-angiotensin system (RAS) and ACE2, which serves as a main entry site to the human host while normally being protective for the lungs. Additionally, it has been observed that patients with hypertension more often had a severe course of COVID-19 compared with those with normal blood pressure [36, 37].

Characteristics of Chinese patients showed that diabetes, hypertension and cardiovascular disease are common among SARS-CoV-2 positive patients and may be associated with poor outcomes. Usually patients who suffer from cardiovascular diseases are older and therefore they have a worse functioning immune system that is less able to fight infections [38]. One potential explanation of these results is that bilateral pneumonia is capable of deterioration of the blood oxygenation within lungs, which in turn leads to a poor outcome in patients with cardiac comorbidities, such as heart failure, cardiomyopathies and congenital cyanotic heart diseases. However, the direct relationship is not fully understood $[19,27,28]$.

Despite initial suggestions that the treatment of hypertension and other cardiovascular diseases with RAAS inhibitors may trigger COVID-19 due to altered the virus binding to the receptor ACE2 [39], the European Society of Cardiology and the European Society of Hypertension did not recommend the withdrawal of such therapy. While ACE2 is considered essential for SARS-CoV infection, absence of SARS-CoV was observed in some ACE2 expressing cell types, whereas infection was present in apparently ACE2-deficient cells. It suggests that collateral cofactors may play a role in successful cell infection. More research is needed to elucidate the complex role of the RAAS in connection with SARS-CoV-2 infection [40]. Moreover, the poor outcome of COVID-19 is mainly due to the severity of the lung injury.

The RNA viral genome is released in cytoplasm of host cells and starts rapid replication. The virus can then be released outside the host cell through the cell membrane. The virus directly attacks the lungs and triggers an inflammatory response which affects the heart and vessels as well. Immune system activation is connected with another way of viral invasion, which involves differentiation cluster 209 (CD209) expressed in macrophages [41]. CD209 enables viral entry to immune cells located in the heart and vessels. In severe COVID-19 cases cytokine release storm (CRS) was observed [42]. The cytokines which take part in that process are: IL-2, IL6, IL-7, chemokine C-C motif ligand 2, C-XC motif chemokine 10 (CXCL10), granulocyte colony stimulating factor and tumor necrosis alpha factor (TNF-alpha) [43]. Laboratory tests may reveal increased levels of ferritin, D-dimer, CRP, IL-6, lactate dehydrogenase (LDH) and lymphopenia [44]. Early studies showed that one of those cytokines, IL6, can be a predictor of increased mortality in COVID19 [45]. The inflammatory process may also lead to plaque instability and as a consequence to acute coronary events. Common cardiac disease may be easily mistaken for SARS-CoV-2.

The pathomechanisms of cardiac manifestation of COVID19 are shown in the Fig. 1.

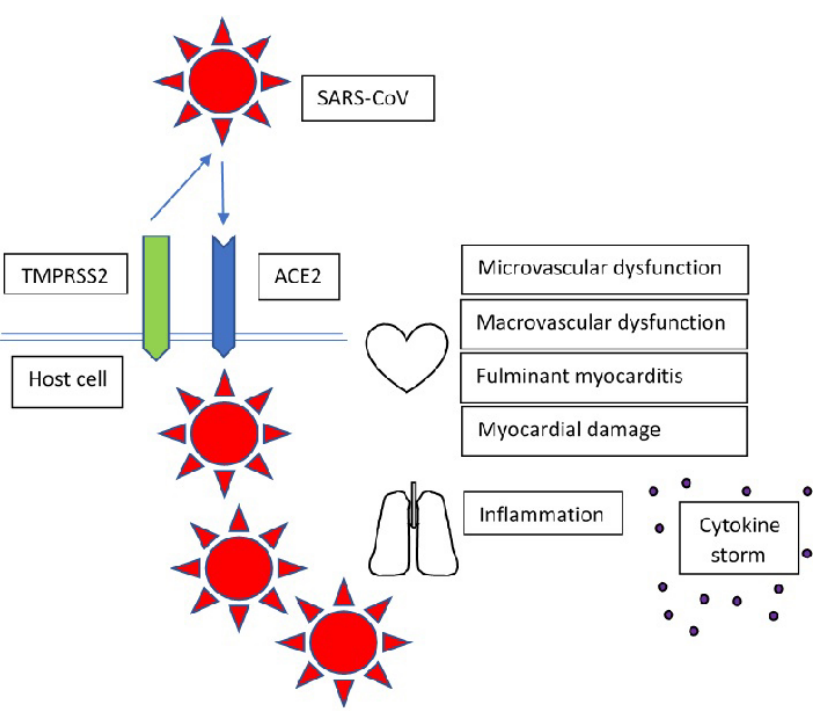

Fig. 1. Pathomechanism of COVID-19 (the SARS-CoV-2 spike protein is activated by TMPRSS2, which allows for its attachment to ACE2. ACE2 receptor is a way for host cell entry. SARS-CoV-2 attacks lungs and heart, leading to dysfunction of heart and cytokine storm).

\subsection{Management approach for patients with COVID-19 associated} cardiovascular involvement

Myocarditis is often suspected in patients with chest pain during or after an influenza-like syndrome, with changes on electrocardiography or laboratory testing suggesting an acute coronary syndrome with wall motion abnormalities but without coronary artery disease on coronary angiography [46]. Some reports of patients presenting cardiac symptoms in COVID-19 infection, myocardial inflammation, necrosis and ventricular dysfunction and arrhythmia shown in Table 1 [47-54] suggest not only myocardial injury but also potentially viral myocarditis or stress cardiomyopathy $[46,55]$. Moreover especially critically ill COVID-19 patients admitted to intensive care unit develop different arrhythmias like sinus bradycardia, and tachycardia, supraventricular tachycardia, atrial fibrillation, and also non-sustained ventricular tachycardia $[49,56]$. COVID-19 patients may be tachycardic due to fever, pain, etc. They can also develop rhythm abnormalities in the setting of prolonged QTc, and electrolyte disturbances, especially high risk patients such as those with pre-existing cardiovascular disease, cancer or combination of both [57]. To date, there is a scarcity of publications mentioning adults with congenital heart defects (ACHD) facing COVID-19 [58]. Because there are no published cases of patients with congenital heart defects, all the management strategies are adapted and based on treating congenital heart 


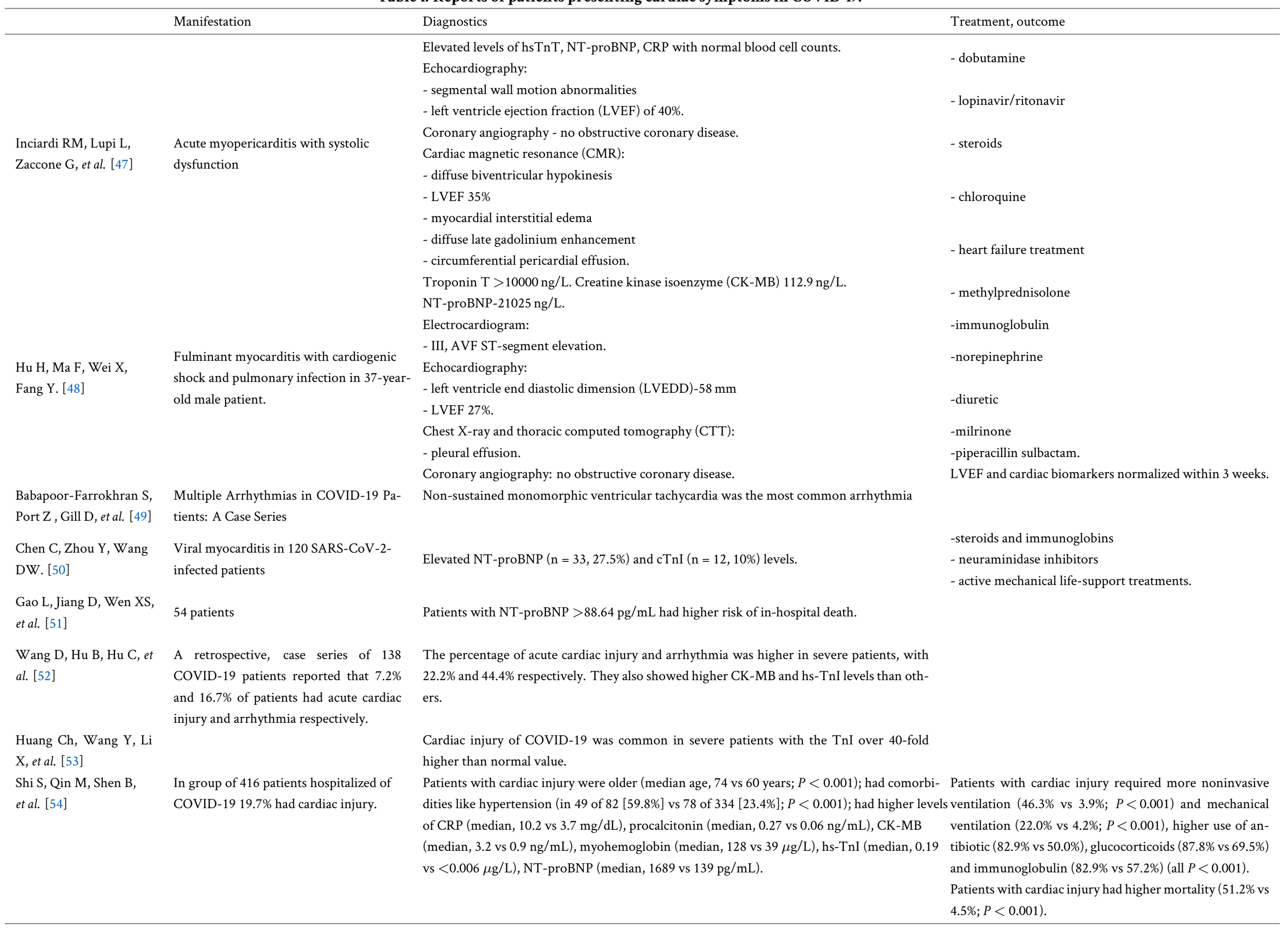


Table 2. Classification of COVID-19 patients-a structured approach to COVID-19 positive patients with heart involvement.

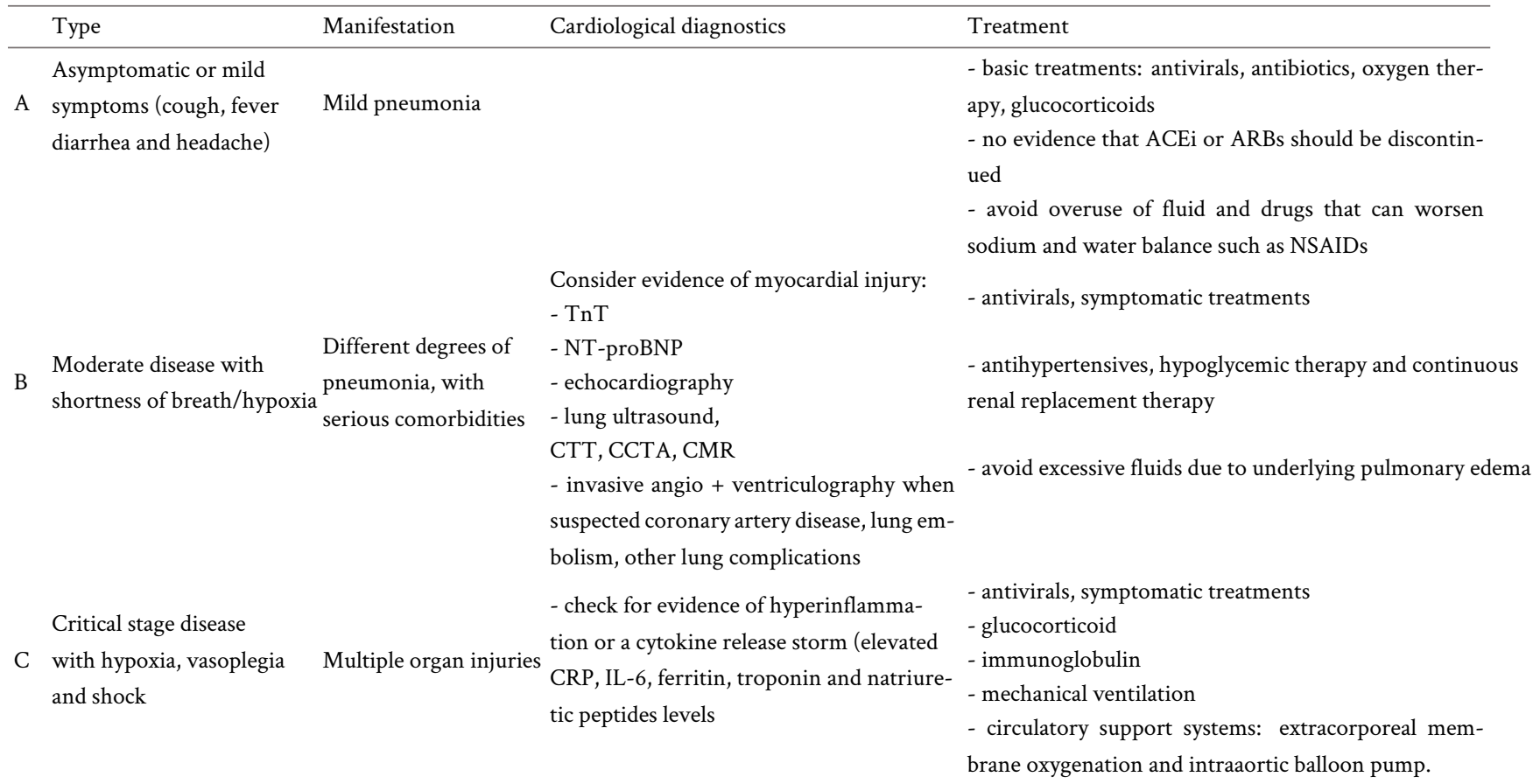

defects like any other cardiovascular morbidity, especially heart failure [59]. It seems logical to perceive grown-up congenital hearts as ones with much higher risk than the general population. According to the ACHD Anatomical and Physiological Stage Classification from the latest American Guidelines, patients with complex congenital heart diseaseanatomical stage III or symptomatic stage B, C, or D-could have high risk for complications related to SARS-CoV-2 infection [60].

These observations suggest a high incidence of lethal cardiac events, arrhythmias, heart failure which are similar to a stress cardiomyopathy or cytokine-related myocardial dysfunction in progressive stages of COVID-19 with fulminant cytokine release. The terminal phase could potentially be avoided by anticytokine therapy such as corticosteroids and the IL-6 blocker tocilizumab [61-63]. Nevertheless, the effect of immunosuppression on the course of this illness is unclear. While in vitro evidence suggests that immunosuppressive medications may inhibit viral replication, long-term such therapy like used for recipients of heart transplant (HT) increases susceptibility to infection [64]. Among twenty-eight HT patients in New York, mycophenolate mofetil was discontinued in $70 \%$ (16 patients), and $26 \%$ (6 patients) had a dose reduction of calcineurin inhibitor [65].

Attempts are being made to develop a structured approach to care of COVID-19 positive patients with heart involvement (Table 2). A classification of these patients in the early stage and algorithms of diagnostics could provide effective triage for the management of patients [62, 66-69].

\section{Conclusions}

Myocardial injury during COVID-19 can be explained by three potential mechanisms: myocardial dysfunction from the direct viral effect on cardiomyocytes-ACE2 mediated direct damage; cardiac injury indirectly due to an excessive immune inflammatory response like cytokine storm; and hypoxia, oxidative stress due to acute respiratory damage resulting in myocardial necrosis from increased myocardial oxygen demand [67]. Cardiovascular diseases are common among SARS-CoV-2 infected patients and can be associated with bad outcomes. It is important to stratify holistic risk by taking all other comorbidities such as diabetes, neurological disorders, disabilities or pulmonary diseases into consideration. Patients diagnosed with COVID-19 may be treated the same way as the general population unless they develop cardiac manifestations. It is necessary to analyze the ECG and measure the levels of biomarkers, such as NTproBNP, troponins, myoglobin, D-dimers, C-reactive protein, interleukin-2, interleukin- 6 and ferritin, to evaluate in a high-risk patients presenting with acute COVID-19, and to help in early detection of patients in need of hospitalization.

\section{Author contributions}

ABD-performed the first literature searching, wrote a first manuscript and revised the final version of article, ACR-performed additional literature searching, wrote the part of the draft and improved the paper, JL-wrote the part of draft and prepare a figure, $\mathrm{FP}$-wrote the epidemiology section and improved a draft, $\mathrm{MM}$ - prepared a table and improved a draft, $\mathrm{MB}-$ revised and improved the draft. All authors contributed to editorial changes in the manuscript. All authors read and approved the final manuscript. 


\section{Ethics approval and consent to participate Not applicable.}

\section{Acknowledgment}

Thanks to all the peer reviewers for their opinions and suggestions. The Project is financed by the Polish National Agency for Academic Exchange under the Foreign Promotion Programme.

\section{Funding}

This research received no external funding.

\section{Conflict of interest}

The authors declare no conflict of interest.

\section{References}

[1] Fung G, Luo H, Qiu Y, Yang D, McManus B. Myocarditis. Circulation Research. 2016; 118: 496-514.

[2] Inciardi RM, Lupi L, Zaccone G, Italia L, Raffo M, Tomasoni D, et al. Cardiac involvement in a patient with coronavirus disease 2019 (COVID-19). Journal of the American Medical Association Cardiology. 2020; 5: 819-824.

[3] Nguyen JL, Yang W, Ito K, Matte TD, Shaman J, Kinney PL. Seasonal influenza infections and cardiovascular disease mortality. Journal of the American Medical Association Cardiology. 2016; 1: 274.

[4] Yu C, Wong RS, Wu EB, Kong S, Wong J, Yip GW, et al. Cardiovascular complications of severe acute respiratory syndrome. Postgraduate Medical Journal. 2006; 82: 140-144.

[5] Esfandiarei M, McManus BM. Molecular biology and pathogenesis of viral myocarditis. Annual Review of Pathology. 2008; 3: 127-155.

[6] Guo Y, Cao Q, Hong Z, Tan Y, Chen S, Jin H, et al. The origin, transmission and clinical therapies on coronavirus disease 2019 (COVID-19) outbreak-an update on the status. Military Medical Research. 2020; 7: 11.

[7] Peng F, Tu L, Yan Y, Hu P, Wang R, Hu Q, et al. Management and treatment of COVID-19: the Chinese experience. Canadian Journal of Cardiology. 2020; 36: 915-930.

[8] Worldometers. COVID-19 Coronavirus Pandemic. 2021. Available at: https://www.worldometers.info/coronavirus/ (Accessed: 19 April 2021).

[9] COVID-19 situation update worldwide, as of week 14. 2021. Available at: https://www.ecdc.europa.eu/en/geographical-distr ibution-2019-ncov-cases (Accessed: 19 April 2021).

[10] WHO-China. Report of the WHO-China joint mission on coronavirus disease 2019 (COVID-19). 2020. Available at: https://www.who.int/docs/default-source/coronaviruse/who-c hina-joint-mission-on-covid-19-final-report.pdf (Accessed: 24 February 2020)

[11] Webb Hooper M, Nápoles AM, Pérez-Stable EJ. COVID-19 and racial/ethnic disparities. Journal of the American Medical Association. 2020; 323: 2466-2467.

[12] Gao Y, Ding M, Dong X, Zhang J, Kursat Azkur A, Azkur D, et al. Risk factors for severe and critically ill COVID-19 patients: a review. Allergy. 2021; 76: 428-455.

[13] Ruan Q, Yang K, Wang W, Jiang L, Song J. Clinical predictors of mortality due to COVID-19 based on an analysis of data of 150 patients from Wuhan, China. Intensive Care Medicine. 2020; 46: 846-848.

[14] Zhou F, Yu T, Du R, Fan G, Liu Y, Liu Z, et al. Clinical course and risk factors for mortality of adult inpatients with COVID-19 in Wuhan, China: a retrospective cohort study. Lancet. 2020; 395: 1054-1062.
[15] Chen C, Zhou Y, Wang DW. SARS-CoV-2: a potential novel etiology of fulminant myocarditis. Herz. 2020; 45: 230-232.

[16] Gao L, Jiang D, Wen X, Cheng X, Sun M, He B, et al. Prognostic value of NT-proBNP in patients with severe COVID-19. Respiratory Research. 2020; 21: 83.

[17] Guo T, Fan Y, Chen M, Wu X, Zhang L, He T, et al. Cardiovascular implications of fatal outcomes of patients with coronavirus disease 2019 (COVID-19). Journal of the American Medical Association Cardiology. 2020; 5: 811-818.

[18] Huang C, Wang Y, Li X, Ren L, Zhao J, Hu Y, et al. Clinical features of patients infected with 2019 novel coronavirus in Wuhan, China. Lancet. 2020; 395: 497-506.

[19] Wang D, Hu B, Hu C, Zhu F, Liu X, Zhang J, et al. Clinical characteristics of 138 hospitalized patients with 2019 novel coronavirusinfected pneumonia in Wuhan, China. Journal of the American Medical Association. 2020; 323: 1061-1069.

[20] Shi S, Qin M, Shen B, Cai Y, Liu T, Yang F, et al. Association of cardiac injury with mortality in hospitalized patients with COVID-19 in Wuhan, China. Journal of the American Medical Association Cardiology. 2020; 5: 802-810.

[21] Hu H, Ma F, Wei X, Fang Y. Coronavirus fulminant myocarditis saved with glucocorticoid and human immunoglobulin. European Heart Journal. 2020. (in press)

[22] Inciardi RM, Lupi L, Zaccone G, Italia L, Raffo M, Tomasoni D, et al. Cardiac involvement in a patient with coronavirus disease 2019 (COVID-19). Journal of the American Medical Association Cardiology. 2020; 5: 819-824.

[23] Shao F, Xu S, Ma X, Xu Z, Lyu J, Ng M, et al. In-hospital cardiac arrest outcomes among patients with COVID-19 pneumonia in Wuhan, China. Resuscitation. 2020; 151: 18-23.

[24] Richardson S, Hirsch JS, Narasimhan M, Crawford JM, McGinn $\mathrm{T}$, Davidson KW. Presenting characteristics, comorbidities, and outcomes among 5700 patients hospitalized with COVID-19 in the New York City Area. Journal of the American Medical Association. 2020; 323: 2052-2059.

[25] Centers for Disease Control and Prevention. Statistics by Topic, National Center of Health Statistics. 2020. Available at: https:// www.cdc.gov/nchs/fastats/default.htm (Accessed: 1 May 2020).

[26] Ganatra S, Dani SS, Redd R, Rieger-Christ K, Patel R, Parikh R, et al. Outcomes of COVID-19 in patients with a history of cancer and comorbid cardiovascular disease. Journal of the National Comprehensive Cancer Network. 2020; 1-10.

[27] Xu Z, Shi L, Wang Y, Zhang J, Huang L, Zhang C, et al. Pathological findings of COVID-19 associated with acute respiratory distress syndrome. Lancet Respiratory Medicine. 2020; 8: 420-422.

[28] Shi S, Qin M, Shen B, Cai Y, Liu T, Yang F, et al. Association of cardiac injury with mortality in hospitalized patients with COVID-19 in Wuhan, China. Journal of the American Medical Association Cardiology. 2020; 5: 802-810.

[29] Xiong T, Redwood S, Prendergast B, Chen M. Coronaviruses and the cardiovascular system: acute and long-term implications. European Heart Journal. 2020; 41: 1798-1800.

[30] Yu C, Wong RS, Wu EB, Kong S, Wong J, Yip GW, et al. Cardiovascular complications of severe acute respiratory syndrome. Postgraduate Medical Journal. 2006; 82: 140-144.

[31] Walls AC, Park Y, Tortorici MA, Wall A, McGuire AT, Veesler D. Structure, function, and antigenicity of the SARS-CoV-2 spike glycoprotein. Cell. 2020; 181: 281-292.e6.

[32] Yan R, Zhang Y, Li Y, Xia L, Guo Y, Zhou Q. Structural basis for the recognition of SARS-CoV-2 by full-length human ACE2. Science. 2020; 367: 1444-1448.

[33] Santos RAS, Sampaio WO, Alzamora AC, Motta-Santos D, Alenina $\mathrm{N}$, Bader $\mathrm{M}$, et al. The ACE2/Angiotensin-(1-7)/MAS axis of the renin-angiotensin system: focus on angiotensin-(1-7) physiological reviews. 2018; 98: 505-553.

[34] Li W, Moore MJ, Vasilieva N, Sui J, Wong SK, Berne MA, et al. Angiotensin-converting enzyme 2 is a functional receptor for the SARS coronavirus. Nature. 2003; 426: 450-454.

[35] Hoffmann M, Kleine-Weber H, Schroeder S, Krüger N, Herrler $\mathrm{T}$, Erichsen S, et al. SARS-CoV-2 cell entry depends on ACE2 and 
TMPRSS2 and is blocked by a clinically proven protease inhibitor. Cell. 2020; 181: 271-280.e8.

[36] Zhou F, Yu T, Du R, Fan G, Liu Y, Liu Z, et al. Clinical course and risk factors for mortality of adult inpatients with COVID-19 in Wuhan, China: a retrospective cohort study. Lancet. 2020; 395: 1054-1062.

[37] Walls AC, Park Y, Tortorici MA, Wall A, McGuire AT, Veesler D. Structure, function, and antigenicity of the SARS-CoV-2 spike glycoprotein. Cell. 2020; 181: 281-292.e6.

[38] Guan WJ, Ni ZY, Hu Y, Liang WH, Ou CQ, He JX, et al. China medical treatment expert group for Covid-19. Clinical characteristics of coronavirus disease 2019 in China. New England Journal of Medicine. 2020; 382: 1708-1720.

[39] Kuster GM, Pfister O, Burkard T, Zhou Q, Twerenbold R, Haaf P, et al. SARS-CoV2: should inhibitors of the renin-angiotensin system be withdrawn in patients with COVID-19? European Heart Journal. 2020; 41: 1801-1803.

[40] Gu J, Korteweg C. Pathology and pathogenesis of severe acute respiratory syndrome. American Journal of Pathology. 2007; 170: 1136-1147.

[41] Li Z, Guo X, Hao W, Wu Y, Ji Y, Zhao Y, et al. The relationship between serum interleukins and T-lymphocyte subsets in patients with severe acute respiratory syndrome. Chinese Medical Journal. 2003; 116: 981-984.

[42] Ganatra S, Dani SS, Shah S, Asnani A, Neilan TG, Lenihan D, et al. Management of cardiovascular disease during coronavirus disease (COVID-19) pandemic. Trends in Cardiovascular Medicine. 2020; 30: $315-325$.

[43] Huang C, Wang Y, Li X, Ren L, Zhao J, Hu Y, et al. Clinical features of patients infected with 2019 novel coronavirus in Wuhan, China. Lancet. 2020; 395: 497-506.

[44] Clerkin KJ, Fried JA, Raikhelkar J, Sayer G, Griffin JM, Masoumi A, et al. COVID-19 and cardiovascular disease. Circulation. 2020; 141: $1648-1655$.

[45] Ruan Q, Yang K, Wang W, Jiang L, Song J. Clinical predictors of mortality due to COVID-19 based on an analysis of data of 150 patients from Wuhan, China. Intensive Care Medicine. 2020; 46: 846-848.

[46] Esfandiarei M, McManus BM. Molecular biology and pathogenesis of viral myocarditis. Annual Review of Pathology. 2008; 3: 127-155.

[47] Inciardi RM, Lupi L, Zaccone G, Italia L, Raffo M, Tomasoni D, et al. Cardiac involvement in a patient with coronavirus disease 2019 (COVID-19). Journal of the American Medical Association Cardiology. 2020; 5: 819-824.

[48] $\mathrm{Hu} \mathrm{H}, \mathrm{Ma} \mathrm{F}$, Wei X, Fang Y. Coronavirus fulminant myocarditis saved with glucocorticoid and human immunoglobulin. European Heart Journal. 2020.

[49] Babapoor-Farrokhran S, Port Z, Gill D, Ammari Z, Mainigi S, Amanullah A. Multiple arrhythmias in COVID-19 patients: a case series. Annals of Cardiology. 2020; 1: 2.

[50] Chen C, Zhou Y, Wang DW. SARS-CoV-2: a potential novel etiology of fulminant myocarditis. Herz. 2020; 45: 230-232.

[51] Gao L, Jiang D, Wen X, Cheng X, Sun M, He B, et al. Prognostic value of NT-proBNP in patients with severe COVID-19. Respiratory Research. 2020; $21: 83$.

[52] Wang D, Hu B, Hu C, Zhu F, Liu X, Zhang J, et al. Clinical characteristics of 138 hospitalized patients with 2019 novel coronavirusinfected pneumonia in Wuhan, China. Journal of the American Medical Association. 2020; 323: 1061-1069.

[53] Huang C, Wang Y, Li X, Ren L, Zhao J, Hu Y, et al. Clinical fea- tures of patients infected with 2019 novel coronavirus in Wuhan, China. Lancet. 2020; 395: 497-506.

[54] Shi S, Qin M, Shen B, Cai Y, Liu T, Yang F, et al. Association of cardiac injury with mortality in hospitalized patients with COVID-19 in Wuhan, China. Journal of the American Medical Association Cardiology. 2020; 5: 802-810.

[55] Clerkin KJ, Fried JA, Raikhelkar J, Sayer G, Griffin JM, Masoumi A, et al. COVID-19 and cardiovascular disease. Circulation. 2020; 141: $1648-1655$.

[56] Lazzerini PE, Boutjdir M, Capecchi PL. COVID-19, Arrhythmic risk, and inflammation: mind the Gap! Circulation. 2020; 142: 7-9.

[57] Lenihan D, Carver J, Porter C, Liu JE, Dent S, Thavendiranathan $\mathrm{P}$, et al. Cardio-oncology care in the era of the coronavirus disease 2019 (COVID-19) pandemic: an International Cardio-Oncology Society (ICOS) statement. CA: A Cancer Journal for Clinicians. 2020; 70: 480-504.

[58] Tan W, Aboulhosn J. The cardiovascular burden of coronavirus disease 2019 (COVID-19) with a focus on congenital heart disease. International Journal of Cardiology. 2020; 309: 70-77.

[59] Wu Z, McGoogan JM. Characteristics of and important lessons from the coronavirus disease 2019 (COVID-19) outbreak in China: summary of a report of 72314 cases from the Chinese Center for Disease Control and Prevention. Journal of the American Medical Association. 2020; 323: 1239-1242.

[60] Stout KK, Daniels CJ, Aboulhosn JA. AHA/ACC guideline for the managementof adults with congenital heart disease: a report of the American College of Cardiology/American Heart Association task force on clinical practice guidelines. Journal of the American College of Cardiology. 2018; 73: e81-e192.

[61] Ganatra S, Carver JR, Hayek SS, Ky B, Leja MJ, Lenihan DJ, et al. Chimeric antigen receptor T-Cell therapy for cancer and heart. Journal of the American College of Cardiology. 2019; 74: 31533163.

[62] Mehta P, McAuley DF, Brown M, Sanchez E, Tattersall RS, Manson JJ. COVID-19: consider cytokine storm syndromes and immunosuppression. Lancet. 2020; 395: 1033-1034.

[63] Xu X, Han M, Li T, Sun W, Wang D, Fu B, et al. Effective treatment of severe COVID-19 patients with tocilizumab. Proceedings of the National Academy of Sciences of the United States of America. 2020; 117: 10970-10975.

[64] Shen L, Niu J, Wang C, Huang B, Wang W, Zhu N, et al. High-throughput screening and identification of potent broadspectrum inhibitors of coronaviruses. Journal of Virology. 2019; 93: e00023-19.

[65] Latif F, Farr MA, Clerkin KJ, Habal MV, Takeda K, Naka Y, et al. Characteristics and outcomes of recipients of heart transplant with coronavirus disease 2019. Journal of the American Medical Association Cardiology. 2020; 5: 1165-1169.

[66] Wang T, Du Z, Zhu F, Cao Z, An Y, Gao Y, et al. Comorbidities and multi-organ injuries in the treatment of COVID-19. Lancet. 2020; 395: e52.

[67] South AM, Diz DI, Chappell MC. COVID-19, ACE2, and the cardiovascular consequences. American Journal of Physiology-Heart and Circulatory Physiology. 2020; 318: H1084-H1090.

[68] Dani SS, Bagga S, Ganatra S. Editorial commentary: cardiovascular imaging in COVID-19: focus on safety, value, and clinical relevance. Trends in Cardiovascular Medicine. 2021; 31: 17-19.

[69] Ofosu-Barko K, Liu Y, Alkhatib Tamimi F, Al Husami W, Ganatra $\mathrm{S}$, Resnic F, et al. Angiotensin II administration in patients with COVID-19 shock. Critical Pathways in Cardiology. 2021; 20: 100 102. 